\title{
Test of Shear Mechanical Properties of Cassava Stalks
}

\author{
WANG Tao ${ }^{1, a}$, YAN Mei ${ }^{1, b}$ and LI Menglin ${ }^{1, c}$ \\ ${ }^{1}$ College of Mechanical and Electrical Engineering, Hainan University, Haikou 570228, China \\ agxdxyjs@163.com, b854026834@qq.com, c1061897535@qq.com
}

\begin{abstract}
Keywords: Cassava stalks Cutting force Influencing factors
Abstract. The parameters of cassava mechanical properties are very important for the design, dynamic simulation and mathematical model of cassava harvester. In order to study the cassava stalks cutting force, stress, power indicators influencing factors, using WD-200B computer-controlled electronic universal testing machine, orthogonal experiments are conducted to test the cassava stalks cutting force, cutting angle is selected, cutting speed, and cassava cutting parts diameter as the impact factors, results of the research show that when the cutting angle is $60^{\circ}$ and the cutting speed is $250 \mathrm{~mm} / \mathrm{min}$, roots as the cutting site, the diameter in the coarse time, the required cutting force, cutting stress and power reach the maximum capacity.For the same cutting speed case, the cutting force of the middle is the maximum, the root is the next, the cutting force of the tip is the minimum; the stress of central part is the maximum, the root is the next, the smallest is tip stress; the middle has the maximum power, the root is the next, followed by tip power. For the same parts of the stalks, with the thinner diameter from coarse cutting force decreased; gradual decline of power; unrelated stress magnitude and diameter size have nothing to do with the stalks parts in $2.5 \mathrm{MPa}$ fluctuate. With the angle changes, the cutting Force, stress, and power of the tip portion ate significantly lower than the central and root. The study results provide a theoretical basis for grinding cassava stalks harvester developed.
\end{abstract}

\section{Introduction}

Cassava is widely grown in tropical and subtropical regions. Most areas in Hainan have cassava, it is one of Hainan's specialty crops, and brings a lot of benefits for the people's production and living. Have a lot of use of the various parts of the cassava value. It is the fruit of cassava root is known as the title of "King of the starch. Can be consumed by humans, livestock, and can also be processed into feed, can be used as industrial raw materials. In addition, Cassava detoxification swelling, commonly used to treat sores and ringworm [1].The leaves can be used as some feed ingredients. Indians living in the Amazon jungle region of cassava leaves as an herbal use [2].Cassava stalks can be made of the feed, but generally low domestic utilization of cassava stalks. In recent years, with the rising status of cassava economic development strategy, the rational utilization of cassava stalks relationship to the development of the industry as a whole, and even the development of China's agricultural economy.

Therefore, the urgent need to design and development for cassava stalks cutting device and milling machinery. Domestic and foreign specialized theory and test methods of the cassava stalks mechanical characteristics of the small, Yang Wang, research on the physical and mechanical properties of cassava stem parameters [3]. German scholar M.J.O 'Dogherty test research on the physical and mechanical properties of the wheat straw and green straw [4], Sun Li the previous years harvest, dry straw and milky stage of compression, shear properties testing and research [5].Wu Fengsheng research design straw chopper device, using a vertical knife hovering cut, overcome difficulties such as rice and wheat straw's toughness, which is difficult to cut and broken [6]. The Chen Zhengguang corn stalks, a three-point bending, the sheared axial and radial shear test study [7]. Meng Haibo corn the stalks rubbing Chet modified test bench test study [8], most of the above studies slower loading conditions.

Whether the effect of harvest of cassava stalks is good or bad is determined by the factors such as cutting diameter, cutting angle, cutting position and so on. There is a lack of research at home and abroad on the cutting mechanical properties of cassava stalks .Cassava stalks diameter, cutting parts, cutting angle, cutting speed as influencing factors of cutting force, stress, power indicators tested. The 
research on the development of cassava stalks cutting device has both theoretical and practical significance.

\section{Materials and methods}

Sample Preparation. Ten cassava stalks were taken from Dianbai village under the leadership of New Island village committee in Lingshan Town in Meilan District in Haikou. Cassava stalks by the core tissue and housing, and Setsuko dense core organization of stem substantially no strength, whereas the fibers of the housing into an axial distribution. Cassava stalks are mature straw, the average length of about $2 \mathrm{~m}$ thickness ranges. These 10 cassava stalks numbered 1, 2, 3, .. 9, 10 respectively. Then the whole root cassava stalks divided into three parts, namely the tip, middle, roots, and is divided into three parts stalks numbered. ID rules, the former figures represent stalks number, $1,2,3 \ldots 10$, the latter figure 1, 2 and 3, respectively, on behalf of the sample taken from the former No. tip, in the roots. For example, NO 3 cassava stalks, and the tip portion of the number is 31 , the middle of the number is 32 , the root of the number is 33.Respectively measuring the outer diameter of the root of 10 stalks, No. 13 of the stalks outside diameter of $23.70 \mathrm{~mm}$, that is, the outer diameter of the root of the stalks in the No. 1 of $23.70 \mathrm{~mm}$. No. 23 is $28.20 \mathrm{~mm}$. Number 33 is $27.93 \mathrm{~mm}$. Number 43 is $20.30 \mathrm{~mm}$. No. 53 is $15.56 \mathrm{~mm}$. Number 63 is $21.83 \mathrm{~mm}$. Number 73 is $17.78 \mathrm{~mm}$. Number 83 is $19.20 \mathrm{~mm}$. Number 93 is $27.24 \mathrm{~mm}$. No. $10323.72 \mathrm{~mm}$. Approximation with the outer diameter of the root of each stalks to represent the outer diameter of the root cassava stalks. Cassava stalks diameter based on the measured data, the $10 \mathrm{OD}$ data is divided into three groups.

The first set of data is $15.56-19.77 \mathrm{~mm}$, a second set of data for the $19.77-23.98 \mathrm{~mm}$, and the third set of data to 23.98 to $28.20 \mathrm{~mm}$. Cassava stalks diameter divided into coarse, medium, fine three. Stalks outer diameter is located in the first set of data within a thin rod, is located in the third set of data within the range of within the range of the second set of data for the pole, located as a crude lever. For this, thin rod for 5,7,8 pole 1,4,6,10 thick shaft as 2,3,9.

Take fine rods in rod thick shaft 3 for the experimental material. From the tip portion of each of the rod, the middle root sawn sample Sec length of $150 \mathrm{~mm}$, and the corresponding label affixed on the specimen, respectively. The order in the table according to the orthogonal experiment Experimental these thirty-six samples numbered $1,2,3, \ldots, 35,36$. It is shown in Figure 1: Figure cassava stalks sample numbers.

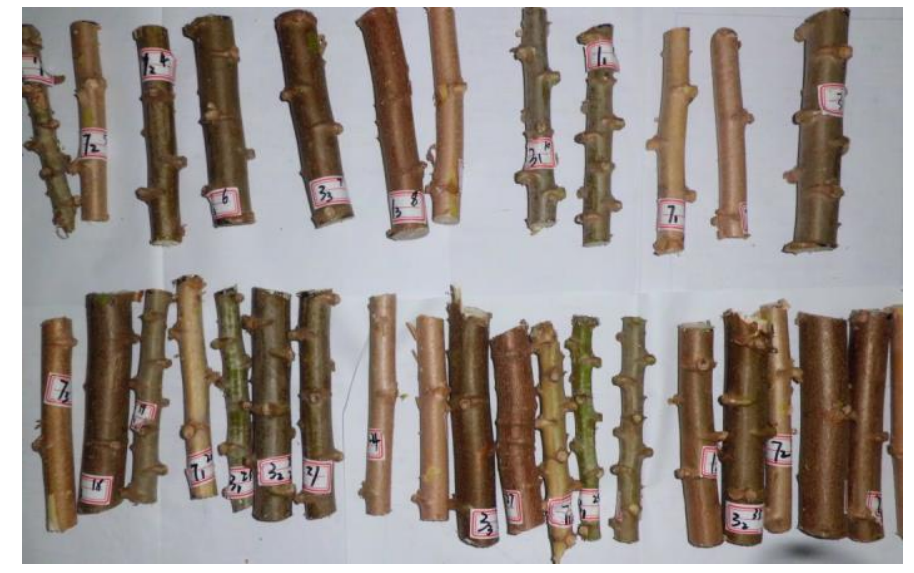

Figure 1 Cassava stalks sample numbers

Test Instrument. Laboratory instruments and equipment for WD-200B microcomputer controlled electronic universal testing machine, protractor, tape measure, micrometer, hacksaw, label support base. WD-200B computer-controlled electronic universal testing machine for the main test instrument, its role is to cut the cassava stalks sample at a different set of universal testing machine speed to test the impact of cutting speed on cutting force and show the changes of the value of the cutting force by computer. 
Protractor plays the role of cutting angle measurement and control. Measuring tape and a micrometer is used to measure the physical parameters of the cassava straw tape measure to measure the length of the cassava straw, the cassava stalks micrometer, measure the outside diameter, inside diameter and thickness. Hacksaw from the field, from the amputated cassava stalks, and the sample was produced by sawing the length in accordance with the regulations of the various parts of the cassava straw. The tags used to mark the sample, facilitate cassava Straw each sample parameter measurement and recording. The support base is a device to support cassava straw sample during the cutting experiments.

Methods. Use of WD - 200 - b microcomputer control electronic universal testing machine for good sample for cutting experiment, according to a set of experimental condition is different, different types of cutting experiments. Cutting speed change through the electronic universal testing machine control, speed change to $50 \mathrm{~mm} / \mathrm{min}, 100 \mathrm{~mm} / \mathrm{min}, 250 \mathrm{~mm} / \mathrm{min}$ only in electronic universal testing machine set corresponding speed value can be. The change of the cutting Angle is through the control anchorage and experimental platform to realize the change of Angle.

When the blade and cassava straw sample between the cutting Angle of $30^{\circ}$, the control anchorage and experimental platform for Angle $60^{\circ}$. When the blade and cassava straw sample between the cutting Angle $45^{\circ}$, the control anchorage and experimental platform for Angle $45^{\circ}$. When the blade and cassava straw sample between the cutting Angle is $60^{\circ}$, the control anchorage and experimental platform Angle of $30^{\circ}$. When the blade and cassava straw sample between the cutting Angle is $90^{\circ}$, the cassava straw sample level of placed in the anchorage. Cutting parts of the change in the preparation material phase has been completed, and the cassava straw into tip department, central and root. It is shown in figure 2 : cassava straight cut $90^{\circ}$ loading installation drawing. Figure 3 for cassava straw oblique loading installation drawing. Figure 4 for cassava straw to cut off the map. Figure 5 for experimental device structure diagram.

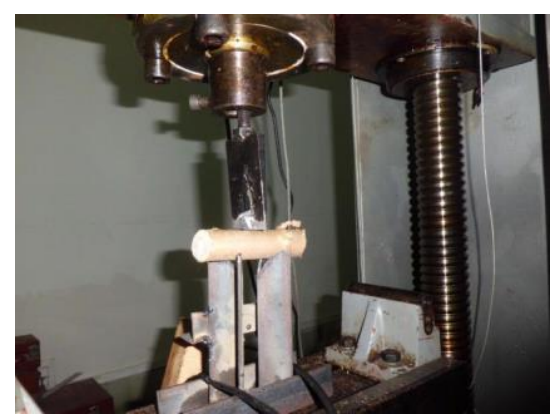

Figure 2 Cassava straight cut $90^{\circ}$ loading installation drawing

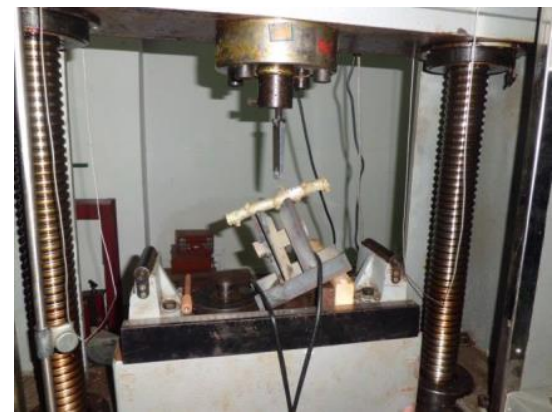

Figure 3 For oblique cutting $45^{\circ}$ loading installation drawing 


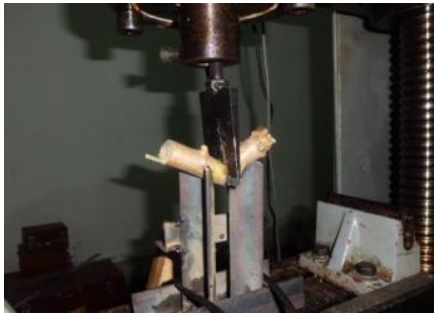

Figure 4 Cassava straw to cut off the map

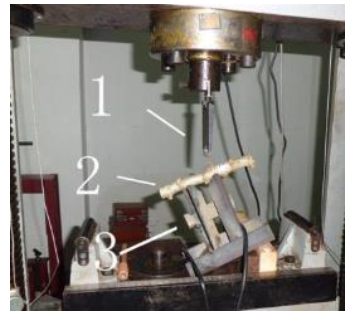

1 blade 2 cassava stem 3 support Figure 5 Experiment device structure

The Impact of Cutting Force, Stress, Power Orthogonal Test. To select cutting angle, cutting speed, cutting site, and cassava rod diameter as the main influencing factors, and to study the impact of the cassava stalks cutting, cutting force, stress, power, and other indicators. Factors and level of inspection to schedule the test results to use the $\mathrm{L}^{36}\left(4 \times 3^{10}\right)$ orthogonal table, and can arrange a four-level factors and factors of three and three levels orthogonal test. Test indicators optional straw cut when the cutting force, stress, power. It is shown in Table 1: Test factor in the level of the table.

Table1: Test factor in the level of the table

$\begin{array}{ccccc}\begin{array}{c}\text { level } \\ \text { factor }\end{array} & \left.\text { Cutting angle } \mathrm{A}^{\circ}\right] & \begin{array}{c}\text { Cutting speed } \\ \mathrm{B}[\mathrm{mm} / \mathrm{min}]\end{array} & \text { Cutting parts } \mathrm{C} & \text { Diameter D } \\ 1 & 30 & 50 & \text { tress tip } & \text { thick } \\ 2 & 45 & 100 & \text { meddle } & \text { medium } \\ 3 & 60 & 250 & \text { root } & \text { fine } \\ 4 & 90 & & & \end{array}$

Cutting Force, Stress, the Power with the Cutting Speed Change Experiments. During the experiment, the experimental variable cutting speed were taken as $50 \mathrm{~mm} / \mathrm{min} 100 \mathrm{~mm} / \mathrm{min}$ $250 \mathrm{~mm} / \mathrm{min}$. Cassava stalks approximately the same diameter, cutting angle is 90 . Taken outside diameter approximately the same tip, the middle of the roots, the material sample numbers were $71,42,83$ the. From the tip portion of each of the rod, the middle root sawing out three sections of the specimen with a length of $100 \mathrm{~mm}$, and the corresponding label affixed on the specimen, respectively. The sequence according to the present experiment, this nine sample number is $37,38, \ldots 44,45$. Cutting test, and record the data of the straw is cut off when the cutting force, the calculated cutting stress and cutting power.

Cutting Force, Stress, Power Change in the Diameter of Experiments. During the experiment, the experimental variables cassava straw diameter, divided into coarse, medium, fine. Control variable cutting speed of $250 \mathrm{~mm} / \mathrm{min}$, and a cutting angle of $90^{\circ}$. As a crude and an outer diameter approximately the same tip, central, root diameter, were 91,32,103. Each saw a long period for a sample of $100 \mathrm{~mm}$. The diameter and the outer diameter of an approximation of the same tip, central, root, materials Sample No. 101,22,63. Each saw a long period for a sample of $100 \mathrm{~mm}$. Taken into fine diameter and an outer diameter approximately the same tip, central, root, 81,72,53 respectively. Each saw a long period for a sample of $100 \mathrm{~mm}$. And corresponding label affixed on the nine samples, respectively. Again, according to the present order of the experiment, these nine samples are numbered, as $46,47, \ldots 53,54$. Cutting test, and record the data of the straw is cut off when the cutting force, the calculated cutting stress and cutting power. 
Cutting Force, Stress, Power with Cutting Angle Change Experiments. During the experiment, the variable cutting angle, divided into $30^{\circ}, 45^{\circ}, 60^{\circ}, 90^{\circ}$. The outer diameter of the control variables cassava stalks approximately the same cutting speed $250 \mathrm{~mm} / \mathrm{min}$. Taken outside diameter approximately the same tip, central, root, material samples were numbered 81,82,53. From the tip portion of each of the rod, the middle root sawing out three sections of the specimen with a length of $100 \mathrm{~mm}$, and the corresponding label affixed on the specimen, respectively. According to the sequence of the present experiment, the nine sample numbers are $55,56, \ldots, 65$ and 66 . Cutting test, and record the data of the straw is cut off when the cutting force, the calculated cutting stress and cutting power.

\section{Results and discussion}

Orthogonal Experiment Results. Sequentially according to the order of the table of the orthogonal experiment design experimental groups experiment. Orthogonal experiment Table 2 as follows: 
Table 2: Design and Results of orthogonal experiment

\begin{tabular}{|c|c|c|c|c|c|c|}
\hline $\begin{array}{l}\text { Numer } \\
\text { order } \\
\text { Factor }\end{array}$ & $\begin{array}{c}\text { Cutting } \\
\text { angle } \\
{\left[{ }^{\circ}\right]}\end{array}$ & $\begin{array}{c}\text { Cutting } \\
\text { speed } \\
{[\mathrm{mm} / \mathrm{min}]}\end{array}$ & $\begin{array}{c}\text { Cutting } \\
\text { parts }\end{array}$ & Diameter & $\begin{array}{c}\text { Cutting } \\
\text { force } \\
{[\mathrm{KN}]}\end{array}$ & $\begin{array}{c}\text { Power } \\
\text { [W] }\end{array}$ \\
\hline
\end{tabular}

\begin{tabular}{|c|c|c|c|c|c|c|c|}
\hline 1 & $1(30)$ & $1(50)$ & 1 (tress tip) & 3 (fine) & 0.3236 & 2.52988 & 0.2697 \\
\hline 2 & $1(30)$ & $2(100)$ & 1 (tress tip) & 1(thick) & 0.2186 & 1.70632 & 0.3643 \\
\hline 3 & $1(30)$ & $3(250)$ & 1(tress tip) & $\begin{array}{l}\text { 2(mediu } \\
\mathrm{m})\end{array}$ & 0.2108 & 1.95940 & 0.8783 \\
\hline 4 & $1(30)$ & $1(50)$ & 2(middle) & $\begin{array}{c}\text { 2(mediu } \\
\mathrm{m})\end{array}$ & 0.677 & 2.61891 & 0.5642 \\
\hline 5 & $1(30)$ & $2(100)$ & 2(middle) & 3(fine) & 0.6611 & 3.57995 & 1.1018 \\
\hline 6 & $1(30)$ & $3(250)$ & 2(middle) & 1(thick) & 1.4291 & 3.16021 & 5.9546 \\
\hline 7 & $1(30)$ & $1(50)$ & 3(root) & 1(thick) & 1.5429 & 2.99698 & 1.2858 \\
\hline 8 & $1(30)$ & $2(100)$ & 3(root) & $\begin{array}{c}2 \text { (mediu } \\
\mathrm{m})\end{array}$ & 1.6393 & 3.83473 & 2.7322 \\
\hline 9 & $1(30)$ & $3(250)$ & 3(root) & 3(fine) & 0.6373 & 3.05472 & 2.6554 \\
\hline 10 & $3(60)$ & $1(50)$ & 1(tress tip) & 1(thick) & 0.3694 & 2.37211 & 0.3078 \\
\hline 11 & $3(60)$ & $2(100)$ & 1(tress tip) & $\begin{array}{c}\text { 2(mediu } \\
\mathrm{m})\end{array}$ & 0.4545 & 2.45324 & 0.7575 \\
\hline 12 & $3(60)$ & $3(250)$ & 1 (tress tip) & 3 (fine) & 0.4527 & 3.13530 & 1.8863 \\
\hline 13 & $3(60)$ & $1(50)$ & 2(middle) & 3(fine) & 0.946 & 5.03466 & 0.7883 \\
\hline 14 & $3(60)$ & $2(100)$ & 2(middle) & 1(thick) & 1.0371 & 2.48580 & 1.7285 \\
\hline 15 & $3(60)$ & $3(250)$ & 2(middle) & $\begin{array}{l}\text { 2(mediu } \\
\text { m) }\end{array}$ & 1.4135 & 3.49002 & 5.8896 \\
\hline 16 & $3(60)$ & $1(50)$ & 3 (root) & $\begin{array}{l}\text { 2(mediu } \\
\mathrm{m})\end{array}$ & 1.6106 & 3.78178 & 1.3422 \\
\hline 17 & $3(60)$ & $2(100)$ & 3(root) & 3(fine) & 0.9961 & 3.95544 & 1.6602 \\
\hline 18 & $3(60)$ & $3(250)$ & $3(r)$ & 1(thick) & 1.8614 & 3.19936 & 7.7558 \\
\hline 19 & $4(90)$ & $1(50)$ & 1(tress tip) & $\begin{array}{l}\text { 2(mediu } \\
\mathrm{m})\end{array}$ & 0.2985 & 1.74083 & 0.2488 \\
\hline 20 & $4(90)$ & $2(100)$ & 1(tress tip) & 3(fine) & 0.3137 & 2.13606 & 0.5228 \\
\hline 21 & $4(90)$ & $3(250)$ & 1 (tress tip) & 1(thick) & 0.2825 & 1.85158 & 1.1771 \\
\hline 22 & $4(90)$ & $1(50)$ & 2(middle) & 1(thick) & 1.1891 & 2.83396 & 0.9909 \\
\hline 23 & $4(90)$ & $2(100)$ & 2(middle) & $\begin{array}{l}\text { 2(mediu } \\
\mathrm{m})\end{array}$ & 0.75 & 2.27258 & 1.2500 \\
\hline 24 & $4(90)$ & $3(250)$ & 2(middle) & 3(fine) & 0.6315 & 3.83479 & 2.6313 \\
\hline 25 & $4(90)$ & $1(50)$ & 3 (root) & 3(fine) & 0.6662 & 2.78057 & 0.5552 \\
\hline 26 & $4(90)$ & $2(100)$ & 3(root) & 1(thick) & 1.6113 & 3.06307 & 2.6855 \\
\hline 27 & $4(90)$ & $3(250)$ & 3 (root) & $\begin{array}{l}\text { 2(mediu } \\
\text { m) }\end{array}$ & 2.1361 & 4.00985 & 8.9004 \\
\hline 28 & $2(45)$ & $1(50)$ & 1(tress tip) & 3(fine) & 0.2759 & 2.00060 & 0.2299 \\
\hline 29 & $2(45)$ & $2(100)$ & 1(tress tip) & 1(thick) & 0.1627 & 1.33358 & 0.2712 \\
\hline 30 & $2(45)$ & $3(250)$ & 1(tress tip) & $\begin{array}{l}\text { 2(mediu } \\
\mathrm{m})\end{array}$ & 0.3241 & 2.49530 & 1.3504 \\
\hline 31 & $2(45)$ & $1(50)$ & 2(middle) & $\begin{array}{c}\text { 2(mediu } \\
\text { m) }\end{array}$ & 1.2727 & 3.45857 & 1.0606 \\
\hline 32 & $2(45)$ & $2(100)$ & 2(middle) & 3(fine) & 0.8692 & 4.68575 & 1.4487 \\
\hline 33 & $2(45)$ & $3(250)$ & 2(middle) & 1(thick) & 1.6375 & 3.54615 & 6.8229 \\
\hline 34 & $2(45)$ & $1(50)$ & 3(root) & 1(thick) & 2.0096 & 3.67708 & 1.6747 \\
\hline 35 & $2(45)$ & $2(100)$ & 3 (root) & $\begin{array}{c}2 \text { (mediu } \\
\mathrm{m})\end{array}$ & 1.3262 & 3.16537 & 2.2103 \\
\hline 36 & $2(45)$ & $3(250)$ & 3 (root) & 3(fine) & 0.8224 & 3.46058 & 3.4267 \\
\hline
\end{tabular}


Table 3: Analysis of range for orthogonal experiment

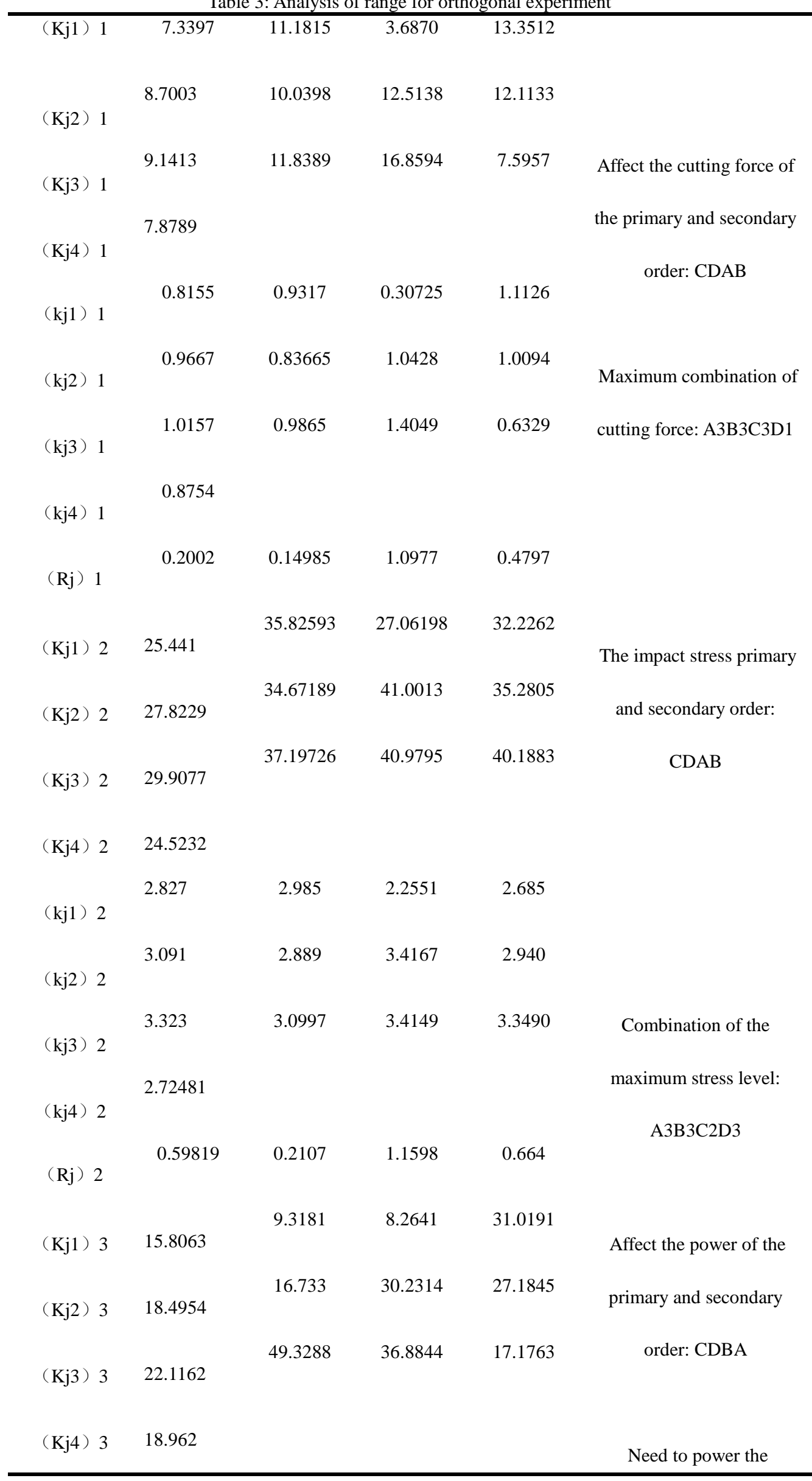




\begin{tabular}{|c|c|c|c|c|c|}
\hline$(\mathrm{Kj} 1) 3$ & 1.756 & 0.7765 & 0.6886 & 2.5849 & maximum \\
\hline$(\mathrm{Kj} 2) 3$ & 2.055 & 1.3944 & 2.519 & 2.2653 & combination:A3B3C3D1 \\
\hline$(\mathrm{Kj} 3)^{3} 3$ & 2.457 & 4.1107 & 3.0737 & 1.4313 & \\
\hline$(\mathrm{Kj} 4) 3$ & 2.1068 & & & & \\
\hline$(\mathrm{Rj}) 3$ & 0.299 & 0.3425 & 2.3851 & 1.1536 & \\
\hline
\end{tabular}

It is shown in table3:the cassava stalks cut off when the cutting force of the main factors: the cutting region $\mathrm{C}$, straw diameter $\mathrm{D}$, cutting angle $\mathrm{A}$ and the cutting speed $\mathrm{B}$. Maximum cutting force of combination: A3B3C3D1, that cutting angle of $60^{\circ}$ and speed $250 \mathrm{~mm} / \mathrm{min}$, cutting parts of the roots, when the straw diameter elected rough cut off required cutting force to the maximum. The possible reason is that the biological fiber structure of the root of the cassava stalk is dense, which consume more energy to finish the stalk cutting, so the cutting force is larger. The larger the diameter of cassava straw is, the more the transverse fibers are cut off, which directly leads to the increase of cutting force. According to the theorem of momentum, the larger the blade speed, the larger the impulsive force we need to cut off the cassava stalk; the larger the cutting angle, the larger the force we need to cut off the structural fibrous tissue.

Cutting parts $\mathrm{C}$ for the order of the main factors affecting the primary and secondary shear stress cut straw straw: straw diameter D, cutting angle A and the cutting speed B. Combination of cut off when the maximum stress level: A3B3C2D3 cutting angle of $60^{\circ}$ and speed $250 \mathrm{~mm} / \mathrm{min}$, cutting parts of central and the straw diameter elected fine cut off when cutting stress. The possible reason is that the cutting stress of cassava straw mainly depends on the strength of the biological materials. The root of cassava stalk is strong, while the strength of the cassava stalk becomes small when the height increases. The diameter of the root of cassava stalk is always the largest and have the largest biological materials strength, so the required cutting stress values will increase dramatically when you want to cut off the root. The smaller the cutting angle is, the smaller the cutting stress is. The main reason is that the shear stress component of the blade to impact the straw section becomes small as the speed decreases, which leads to the decrease of cutting stress. According to the theorem of momentum, the larger the blade speed, the larger the impulsive force. But the fibrous structure of cassava straw will deform when the impulsive force is too large, the cutting stress is not necessarily proportional to the increase.

Primary and secondary order of the the straw stalks cut the power required impact factors: CDBA cutting parts $\mathrm{C}$, straw diameter $\mathrm{D}$, the cutting speed $\mathrm{B}$ and cutting angle $\mathrm{A}$ cut required maximum power combination. A3B3C3D1, namely that cutting angle of $60^{\circ}$ and speed $250 \mathrm{~mm} / \mathrm{min}$, cutting parts of the roots, the straw diameter elected rough cut when cutting power, was the largest.The main factors influencing the straw cutting power is the energy needed to cut off straw. The straw fiber organization is close and the number is of fibers is large when the diameter of the root is large, so the cutting power is large. When the straw fiber is cut forward, the fiber is rapidly deformed and gathered, and the energy consumed by this action is increase, the cutting power needed is greater. As the cutting speed increases, the energy consumption of the machine will be higher, this accords with the principle of energy theorem.

The comprehensive analysis result shows that: when the cutting angle of $60^{\circ}$, the cutting speed of $250 \mathrm{~mm} / \mathrm{min}$, cutting site for roots, the diameter of the crude, the required cutting force, and cutting stress, and needs power reaches the maximum. 
Table 4: Shear test results of cassava stalks

\begin{tabular}{|c|c|c|c|c|c|c|c|c|c|}
\hline \multicolumn{10}{|c|}{ Cutting speed, the outer diameter is approximately the same, and the cutting angle of $90^{\circ}$} \\
\hline $\begin{array}{c}\text { Number } \\
\text { order }\end{array}$ & $\begin{array}{c}\text { Cutting } \\
\text { parts }\end{array}$ & $\begin{array}{c}\text { Outer } \\
\text { diameter } \\
{[\mathrm{mm}]}\end{array}$ & $\begin{array}{c}\text { Thickness } \\
\text { [mm] }\end{array}$ & $\begin{array}{c}\text { Inner } \\
\text { diameter } \\
{[\mathrm{mm}]}\end{array}$ & $\begin{array}{c}\text { Sectional } \\
\text { area } \\
{\left[\mathrm{mm}^{2}\right]}\end{array}$ & $\begin{array}{l}\text { Cutting } \\
\text { speed } \\
{[\mathrm{mm} / \mathrm{min}]}\end{array}$ & $\begin{array}{l}\text { Cutting } \\
\text { force } \\
{[\mathrm{KN}]}\end{array}$ & $\begin{array}{l}\text { Stress } \\
{[\mathrm{MPa}]}\end{array}$ & $\begin{array}{c}\text { Power } \\
{[\mathrm{W}]}\end{array}$ \\
\hline 37 & $\begin{array}{l}\text { Tress } \\
\text { tip }\end{array}$ & 18.86 & 4.69 & 9.48 & 208.6759 & 50 & 0.4908 & 2.3520 & 0.4090 \\
\hline 38 & $\begin{array}{c}\text { Tress } \\
\text { tip }\end{array}$ & 18.80 & 4.48 & 9.84 & 201.4423 & 100 & 0.5330 & 2.6459 & 0.8883 \\
\hline 39 & $\begin{array}{l}\text { Tress } \\
\text { tip }\end{array}$ & 19.06 & 5.53 & 8.00 & 234.9376 & 250 & 0.5561 & 2.3670 & 2.3171 \\
\hline 40 & middle & 19.20 & 5.70 & 7.80 & 241.6230 & 50 & 1.0178 & 4.2123 & 0.8482 \\
\hline 41 & middle & 18.64 & 5.35 & 7.94 & 223.2587 & 100 & 0.7546 & 3.3799 & 1.2577 \\
\hline 42 & middle & 19.18 & 5.62 & 7.94 & 239.2906 & 250 & 0.8834 & 3.6917 & 3.6808 \\
\hline 43 & root & 18.96 & 5.62 & 7.72 & 235.4083 & 50 & 0.6099 & 2.5908 & 0.5083 \\
\hline 44 & root & 18.76 & 5.40 & 7.96 & 226.5322 & 100 & 0.6377 & 2.8151 & 1.0628 \\
\hline 45 & root & 18.26 & 5.40 & 7.46 & 218.0542 & 250 & 0.5852 & 2.6837 & 2.4383 \\
\hline
\end{tabular}

Experiment I : Cutting Force, Stress, Change of Power with the Cutting Speed. In order to study the influence of different cutting speed on cutting force, cutting stress and cutting power of cassava stalks, the experimental data of the influence of cutting speed on the three indexes are obtained and shown in Table 4. In the experiment, the external diameter of cassava stalks were almost the same and the cutting angle was $90^{\circ}$.

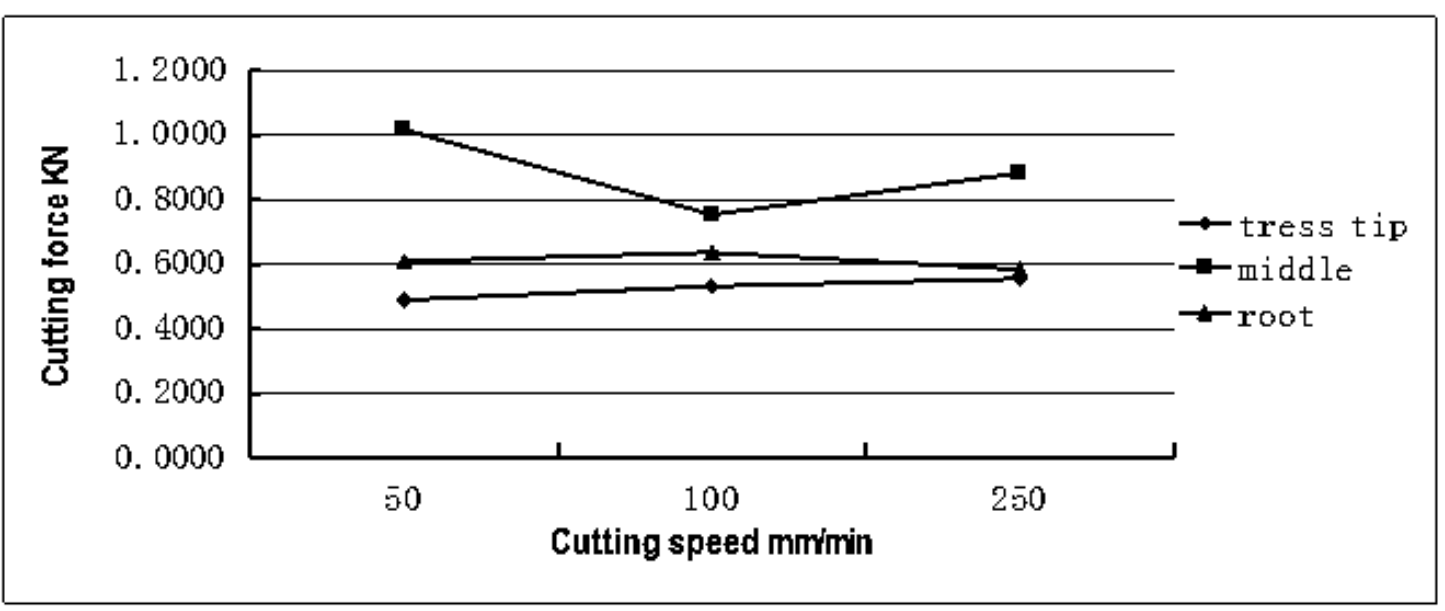

Fig. 6 Effects of cutting speed on cutting force 
It is shown in Figure 6: For the same cutting speed, the cutting force of the central maximum, roots, followed by the tip of the cutting force minimum. The denser the straw fiber is, the greater the cutting force is, the reason is that the peripheral parts of straw is fragile tissue, which have a small number of fibers and the cutting force needed to cut off the straw is small. The experiment results show that the cutting force of the middle stalk is greater than the cutting force of the straw root. Indicating that the fiber in the middle of the straw is very dense, while the water content of straw root is relatively high so that the cutting force is decrease. From what we have discussed above, we can draw a conclusion that we have to make sure that the blade is design to cut off the root of stalk when we doing the design the work of straw cutting harvester, so that we can cut down energy consumption of the machine.

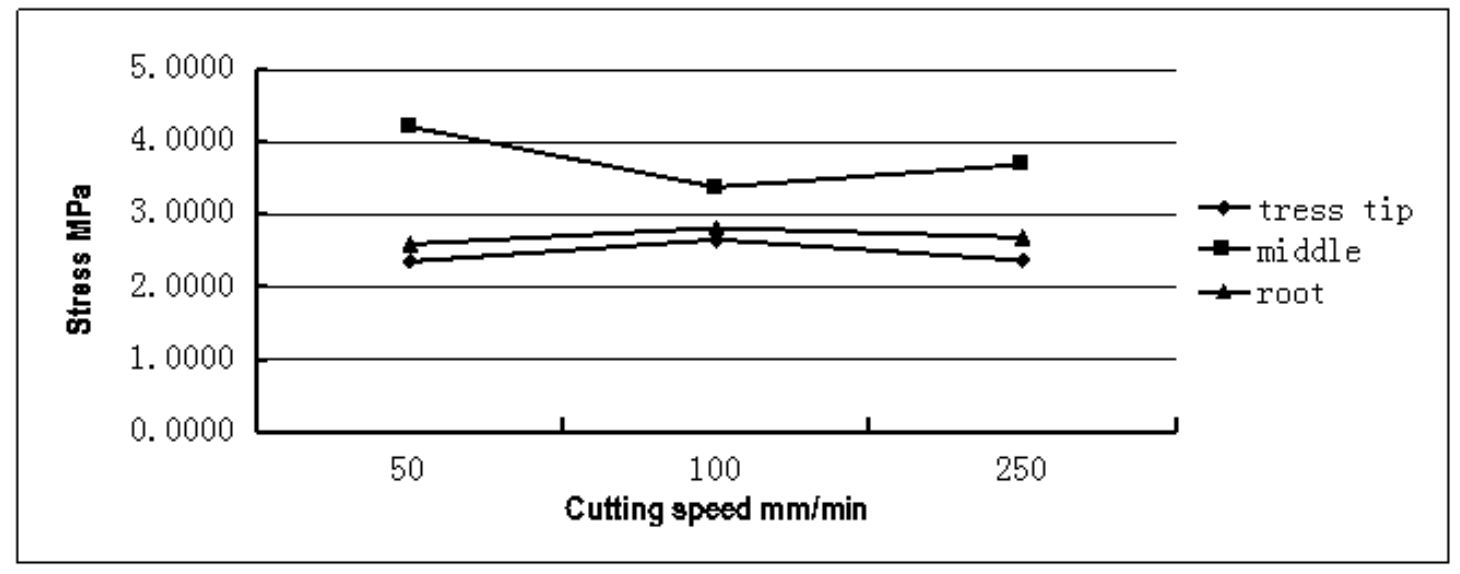

Fig. 7 Effects of cutting speed on stress

It is shown in Figure 7: For the same cutting speed, the middle of the maximum stress, the roots, followed tip portion of the minimum stress. The experimental results show that the strength of the material in the middle of the straw is larger than the strength of the material of the root. The possible reason is that the root of the stalk is close to the cassava fruit, high moisture content leads to less strength of fibrous tissue of the root than the middle of the straw. The rapid growth of the material of the end of the straw makes it weak and low in strength.

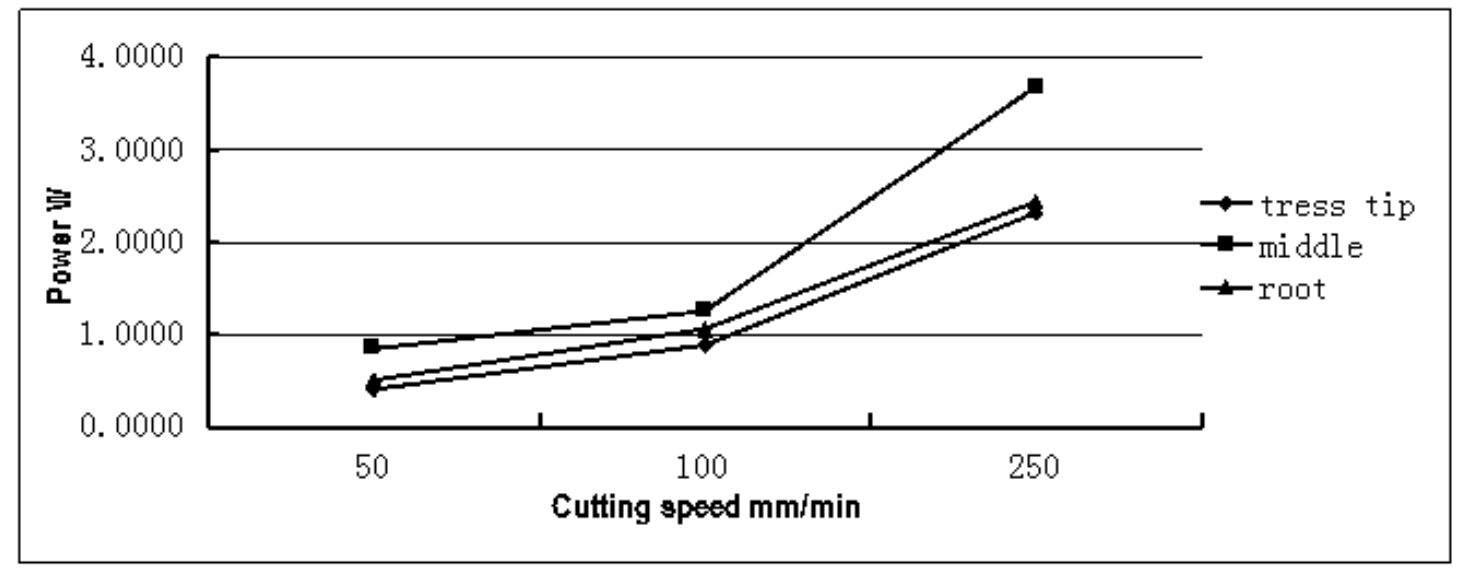

Fig. 8 Effects of cutting speed on power

It is shown in Figure 8: For the same parts of the straw, as the cutting speed increases, the power increases. For the same cutting speed, the power of the central is the maximum, followed by the power of roots, the tip is the minimum. 
Table 5: Shear test results of cassava stalks

Different diameters, the cutting speed of $250 \mathrm{~mm} / \mathrm{min}$, and the cutting angle of $90^{\circ}$

\begin{tabular}{|c|c|c|c|c|c|c|c|c|c|}
\hline \multirow{3}{*}{ Number } & \multirow[b]{3}{*}{ diameter } & \multicolumn{3}{|c|}{ Outer } & \multirow[t]{2}{*}{ Inner } & \multirow[t]{2}{*}{ Sectional } & \multirow[t]{2}{*}{ Cutting } & \multirow[b]{2}{*}{ Stress } & \multirow[b]{2}{*}{ Power } \\
\hline & & Cutting & & thickness & & & & & \\
\hline & & & diameter & & diameter & area & force & & \\
\hline \multirow[t]{2}{*}{ order } & & parts & & {$[\mathrm{mm}]$} & & & & {$[\mathrm{MPa}]$} & [W] \\
\hline & & & {$[\mathrm{mm}]$} & & {$[\mathrm{mm}]$} & {$\left[\mathrm{mm}^{2}\right]$} & {$[\mathrm{KN}]$} & & \\
\hline \multirow{3}{*}{46} & & Tress & & & & & & & \\
\hline & thick & & 25.80 & 7.78 & 10.24 & 440.2142 & 1.5110 & 3.4324 & 6.2958 \\
\hline & & tip & & & & & & & \\
\hline 47 & thick & middle & 24.84 & 7.19 & 10.46 & 398.4770 & 0.8609 & 2.1605 & 3.5871 \\
\hline \multirow[t]{2}{*}{48} & thick & root & 24.81 & 6.73 & 11.35 & 382.0702 & 1.1706 & 3.0638 & 4.8775 \\
\hline & & Tress & & & & & & & \\
\hline \multirow[t]{2}{*}{49} & medium & & 21.90 & 5.72 & 10.46 & 290.6057 & 0.7701 & 2.6500 & 3.2088 \\
\hline & & tip & & & & & & & \\
\hline 50 & medium & middle & 19.38 & 5.80 & 7.78 & 247.3190 & 0.7259 & 2.9351 & 3.0246 \\
\hline \multirow[t]{2}{*}{51} & medium & root & 20.77 & 5.93 & 8.91 & 276.3238 & 0.5729 & 2.0733 & 2.3871 \\
\hline & & Tress & & & & & & & \\
\hline \multirow[t]{2}{*}{52} & fine & & 16.30 & 4.87 & 6.56 & 174.7853 & 0.3368 & 1.9269 & 1.4033 \\
\hline & & tip & & & & & & & \\
\hline 53 & fine & middle & 16.77 & 5.55 & 5.67 & 195.5309 & 0.6168 & 3.1545 & 2.5700 \\
\hline 54 & fine & root & 16.40 & 5.20 & 6.00 & 182.8736 & 0.5890 & 3.2208 & 2.4542 \\
\hline
\end{tabular}

Experiment II: Cutting Force, Stress, Power with Diameter Changes. In order to study the influence of different diameter on cutting force, cutting stress and cutting power of cassava stalks, the experimental data of the influence of diameter on the three indexes are obtained and shown in Table5. In the experiment, the cutting speed was set to be $250 \mathrm{~mm} / \mathrm{min}$ and the cutting angle was $90^{\circ}$.

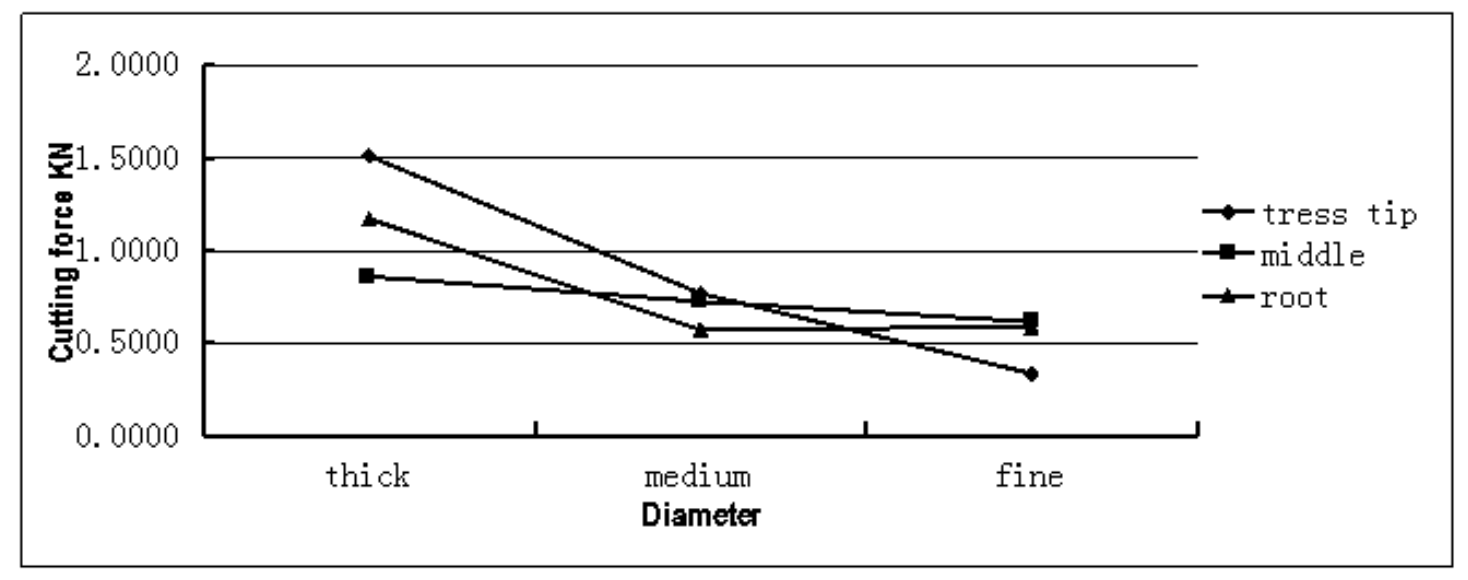

Fig. 9 Effects of diameter on cutting force 
It is shown in Figure 9: straw for the same position, with diameters ranging from coarse to fine cutting force decreased.The reason is that the smaller the diameter, the smaller the number of fibers, the less the cutting force required.

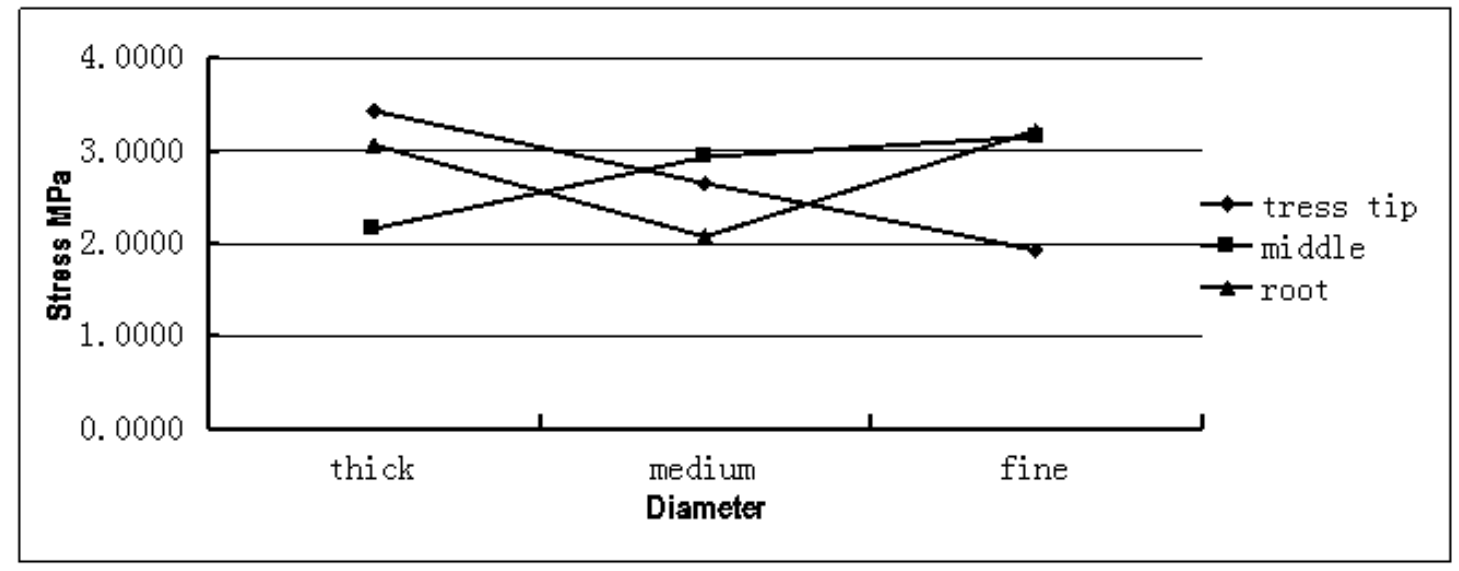

Fig. 10 Effects of diameter on stress

It is shown in Figure 10: stress magnitude and is independent of the diameter, has nothing to do with the straw parts in $2.5 \mathrm{MPa}$ fluctuate. The possible reason is that the strength of the various parts of the straw material is almost the same, the change of the diameter of them are not too large, so that there was no significant difference in the strength of straw in each experiment.

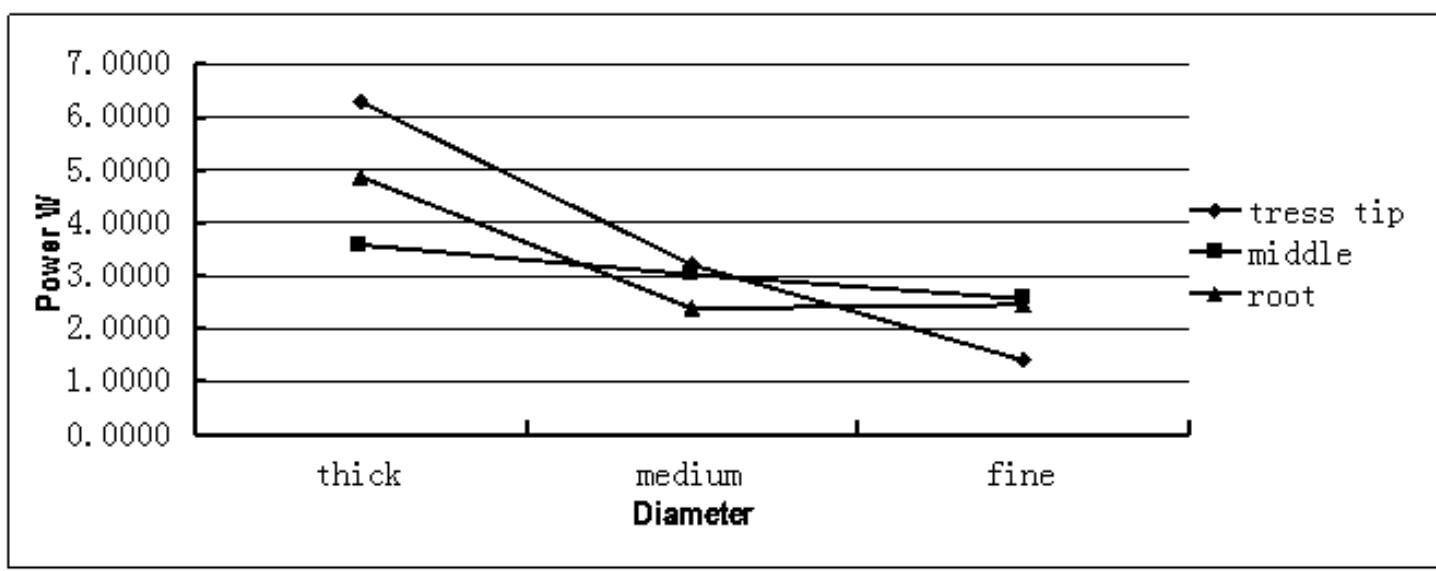

Fig. 11 Effects of diameter on power

It is shown in Figure 11: straw for the same position, with diameters ranging from coarse to fine, the power decreased.The possible reason is that with the reduction of straw materials, the energy needed to cut off materials decreased sharply so that the cutting power decreased gradually. 
Table 6: Shear test results of cassava stalks

Cutting angle is approximately the same outside diameter, cutting speed $250 \mathrm{~mm} / \mathrm{min}$

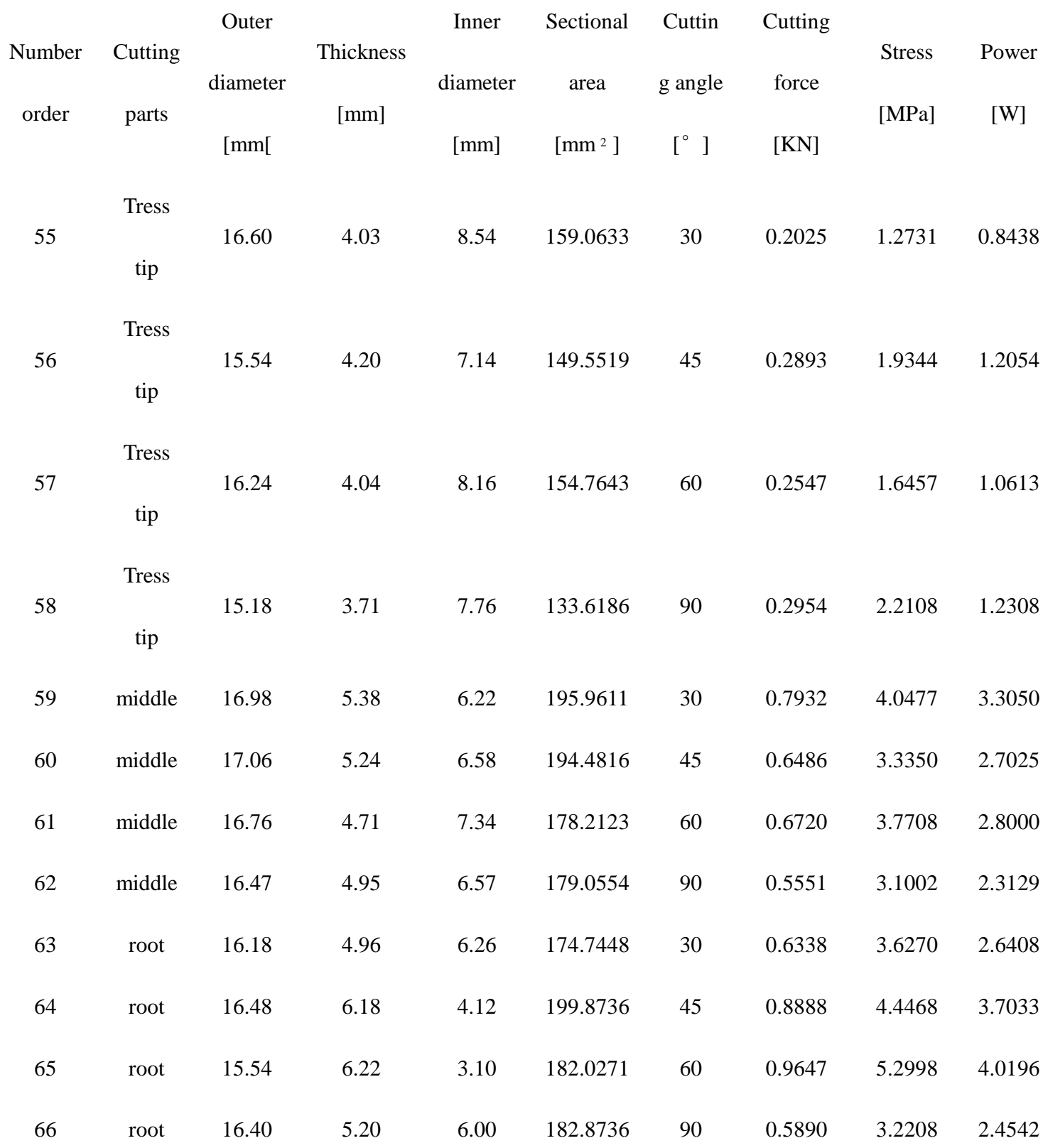

Experiment III: Cutting Force, Stress, the Power with the Cutting Angle Changes. In order to study the influence of different cutting angle on cutting force, cutting stress and cutting power of cassava stalks, the experimental data of the influence of cutting angle on the three indexes are obtained and shown in Table 6 . In the experiment, the external diameter of cassava stalks were almost the same and the cutting speed was set to be $250 \mathrm{~mm} / \mathrm{min}$. 


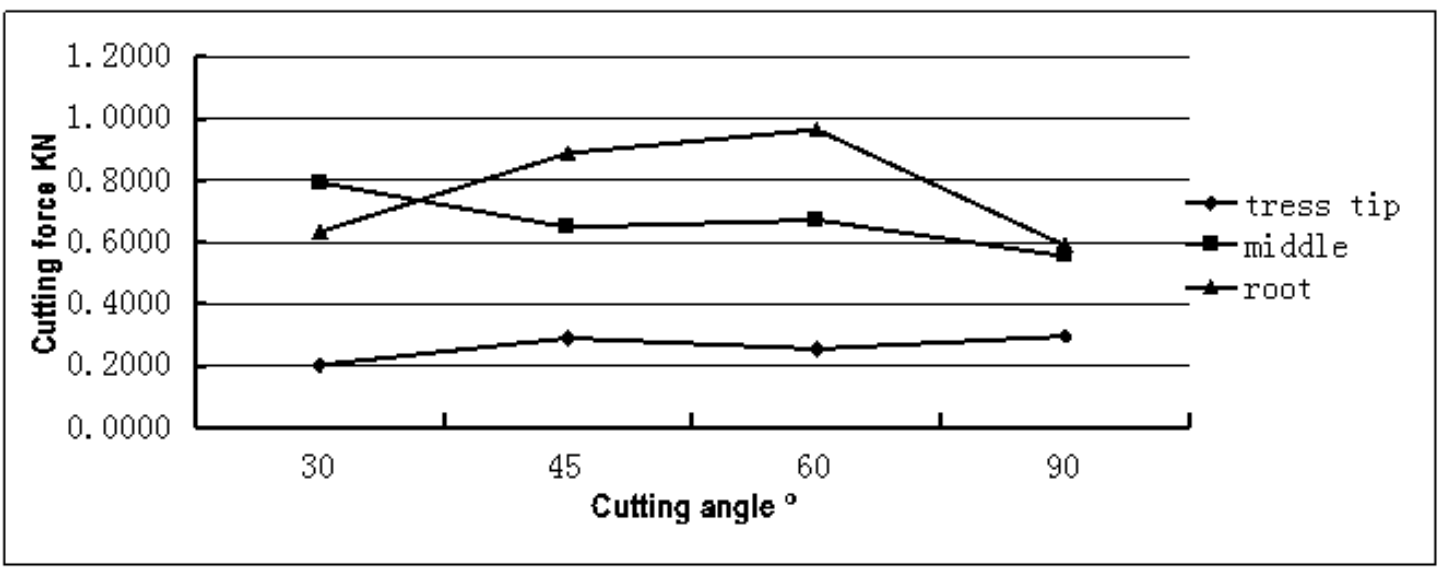

Fig. 12 Effects of cutting angle on cutting force

It is shown in Figure 12: tip portion of the cutting force was significantly lower than the central and the root of the cutting force. That is relevant to the materials used in the experiment. No other obvious rule.

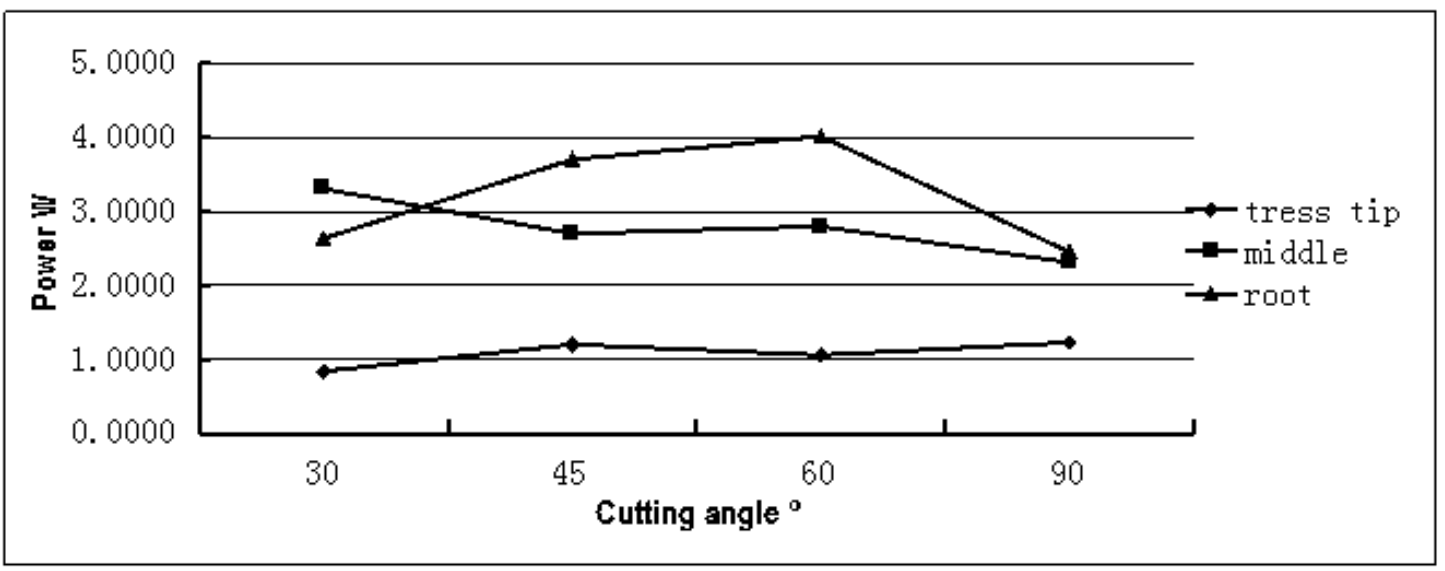

Fig. 13 Effects of cutting angle on power

It is shown in Figure 13: the power is significantly lower than that of the tip portion of the power of the central and roots. That is relevant to the materials used in the experiment. No other obvious rule.

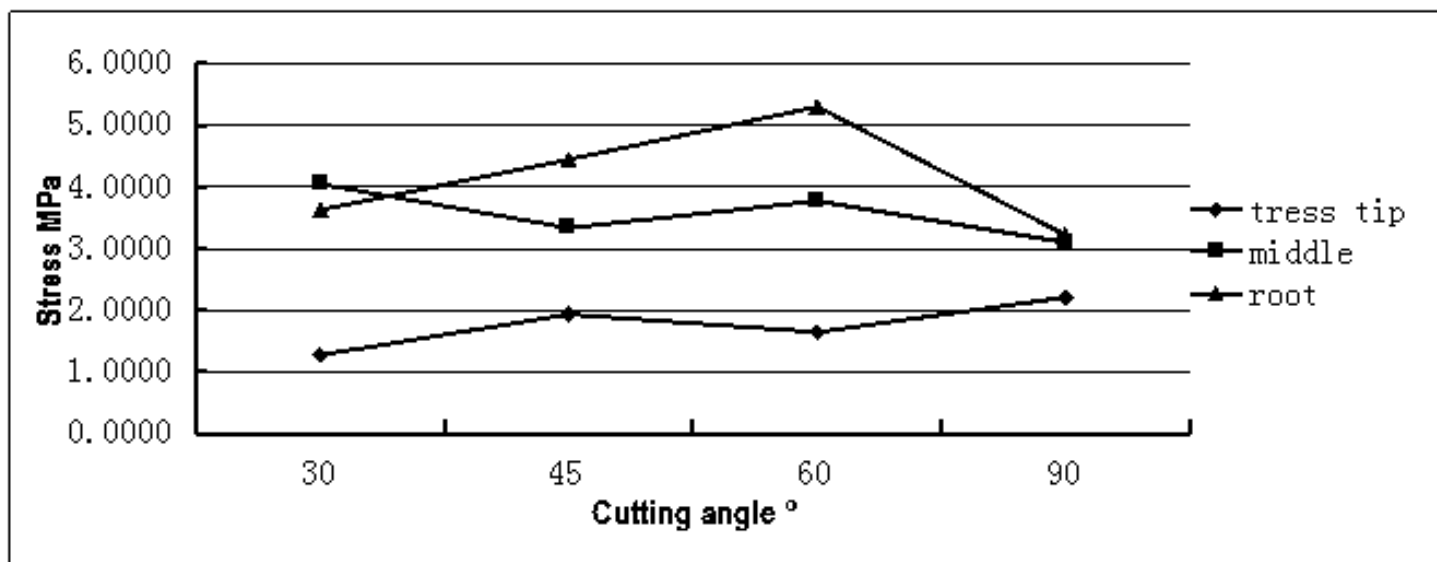

Fig. 14 Effects of cutting angle on stress

It is shown in Figure 14: the stress of the tip was significantly lower than the stress of the central and roots. That is relevant to the materials used in the experiment. No other obvious rule. 


\section{Conclusions}

The investigation of shear mechanical properties of cassava stalks revealed the followings.

(1) when the cutting angle is $60^{\circ}$, the cutting speed is $250 \mathrm{~mm} / \mathrm{min}$, cutting site is the root, the diameter in the coarse time, the required cutting force, cutting stress and power reach the maximum.

(2) for the case of the same cutting speed, the cutting force of the central is the maximum, followed by roots, the cutting force of tip is the minimum; the central part stress is the maximum, the roots as the second, the smallest is the tip stress; maximum power in the middle, the roots as the second, the power of the shoot portion is the minimum.

(3) for the same parts of the straw, the cutting force and power decrease with the diameter changes from coarser to thinner. Stress has nothing to do with the diameter size and straw parts. Floating up or down at $2.5 \mathrm{MPa}$.

(4) with the angle changes, the cutting force, stress, and power of the tip portion are significantly lower than the central and roots.

\section{Acknowledgments}

This work was financially supported by Innovation Research Project of Hainan University (HDCX2012036)

\section{References}

[1] M.Yan, T.Wang, M.L.Li and Y.C.Wang, Y.L.Liao.J. Chin.Agr. Mec Vol. 34(2013).p.70(in Chinese)

[2]I.Kubo, N.Masuoka, K.I.Nihei and B.Burgheim. J.Food.Comps. Anal Vol. 19(2006).p.579

[3]W.Yang, J.Yang, X.T.Zheng, Q.Y.Wang and F.Y.Jia.Trans.CSAE Vol. 27 (Supp.2)(2011).p.50(in Chinese)

[4]M.J. O'Dogherty, J.A. Huber, J. Dyson, C.J. Marshall and J.Agri.Eng. Res Vol. 62(1995).p.133

[5]L.Sun, H.J.Zhao and S.N.Li, Nor.J. Kas Vol. 26(1998).p.106(in Chinese)

[6]F.S.Wu and M.Jin.Trans.CSAE Vol. 14 (1998).p.248(in Chinese)

[7]Z.G.Chen,D.F.Wang, L.Q.Li and R.X.Shan.Trans.CSAE Vol. 28 (2012).p.59(in Chinese)

[8]H.B.Meng,L.J.Han and J.C.Wang. Trans.CSAE Vol. 21 (2005).p.77(in Chinese) 